\title{
The Amyloid Precursor Protein Controls Adult Hippocampal Neurogenesis through GABAergic Interneurons
}

\author{
Baiping Wang, ${ }^{1,2}$ Zilai Wang, ${ }^{1,2}$ Lu Sun, ${ }^{1}{ }^{1}$ Li Yang, ${ }^{1}$ Hongmei Li, ${ }^{1}$ Allysa L. Cole, ${ }^{1}$ Jennifer Rodriguez-Rivera, ${ }^{1}$ \\ Hui-Chen $\mathrm{Lu}^{3,4}$ and Hui Zheng ${ }^{1,2}$ \\ ${ }^{1}$ Huffington Center on Aging, ${ }^{2}$ Department of Molecular and Human Genetics, and ${ }^{3}$ Department of Pediatrics, Baylor College of Medicine, Houston, Texas \\ 77030, and ${ }^{4}$ The Cain Foundation Laboratories, Jan and Dan Duncan Neurological Research Institute at Texas Children's Hospital, Houston, Texas 77030
}

\begin{abstract}
Impaired neurogenesis in the adult hippocampus has been implicated in AD pathogenesis. Here we reveal that the APP plays an important role in the neural progenitor proliferation and newborn neuron maturation in the mouse dentate gyrus. APP controls adult neurogenesis through a noncell-autonomous mechanism by GABAergic neurons, as selective deletion of GABAergic, but not glutamatergic, APP disrupts adult hippocampal neurogenesis. APP, highly expressed in the majority of GABAergic neurons in the dentate gyrus, enhances the inhibitory tone to granule cells. By regulating both tonic and phasic GABAergic inputs to dentate granule cells, APP maintains excitatory-inhibitory balance and preserves cognitive functions. Our studies uncover an indispensable role of APP in the GABAergic system for controlling adult hippocampal neurogenesis, and our findings indicate that APP dysfunction may contribute to impaired neurogenesis and cognitive decline associated with AD.
\end{abstract}

Key words: adult neurogenesis; Alzheimer's disease; amyloid precursor protein; GABAergic; hippocampus; interneurons

\section{Introduction}

The prevailing view of $\mathrm{AD}$ pathogenesis is that abnormal proteolytic processing of APP leads to aberrant production of amyloid- $\beta(\mathrm{A} \beta)$ peptides, which form toxic amyloid oligomers and fibrillar aggregates to elicit a cascade of neurotoxic events, ultimately resulting in synaptic and neuronal dysfunction and neurodegeneration. Accordingly, most of the research in the $\mathrm{AD}$ field has been focused on elucidating the regulation of $A \beta$ and its downstream pathogenic effects. Despite intense effort, our understanding of $\mathrm{AD}$ pathogenesis is still incomplete. One of the important unresolved pieces is the physiological function of APP and whether dysfunction of APP, in an $\mathrm{A} \beta$-dependent or -independent manner, contributes to AD. APP belongs to an evolutionarily conserved family of proteins consisting of APP, amyloid precursor-like protein 1 (APLP1), and APLP2 in mammals. In the CNS APP has been implicated in many biological

Received July 10, 2014; revised Aug. 20, 2014; accepted Aug. 25, 2014.

Author contributions: B.W., Z.W., and H.Z. designed research; B.W., Z.W., L.S., L.Y., H.L., A.L.C., and J.R.-R. performed research; H.-C.L. contributed unpublished reagents/analytic tools; B.W., Z.W., L.S., and L.Y. analyzed data; B.W. and H.Z. wrote the paper.

This work was supported by National Institutes of Health AG032051, AG033467, and AG020670 (to H.Z.) and NS048884 (to H.C.L.). We thank N. Aithmitti for expert technical support, M. Wilson for help in electrophysiology, D. Swartzlander for critical reading of this manuscript, and members of the Zheng lab for helpful and stimulating discussions. We are indebted to the Zoghbi lab (Baylor College of Medicine) for providing the vGAT-Cre mice and the Gage laboratory (Salk Institute) for the gift of retro RFP and retro GFP-Cre constructs. We are grateful to C. Spencer and the Baylor College of Medicine IDDRC Administrative and Mouse Neurobehavioral cores (HD024064) for the generous resources and support.

The authors declare no competing financial interests.

Correspondence should be addressed to either Dr. Hui Zheng or Dr. Baiping Wang, Baylor College of Medicine, One Baylor Plaza, Houston, TX, 77030, E-mail: huiz@bcm.edu or E-mail: baipingw@bcm.edu.

Z. Wang's present address: Department of Developmental Biology, University of Texas Southwestern Medical Center, Dallas, Texas 75390.

DOI:10.1523/JNEUROSCI.2848-14.2014

Copyright $\odot 2014$ the authors $\quad 0270-6474 / 14 / 3413314-12 \$ 15.00 / 0$ processes including cell adhesion, gene transcription, neuronal differentiation, migration, neurite outgrowth, and synapse formation (Zheng and Koo, 2011), although the majority of these proposed functions have not been directly proven in vivo by genetic loss-of-function studies. Disease-causing mutations in APP have been identified in early onset AD patients (Tanzi, 2012), and the pathogenic mechanisms have been attributed to altered production of $\mathrm{A} \beta$. It is conceivable, however, that these mutations could perturb normal APP-processing dynamics and that resulting APP dysfunction could contribute to AD pathogenesis.

Increasing evidence has shown that neurogenesis in the adult hippocampus plays an essential role in learning and memory (Zhao et al., 2008), and that impairment of hippocampal neurogenesis is associated with cognitive impairments in $\mathrm{AD}$ (Mu and Gage, 2011). In the adult hippocampus, dentate granule neurons are generated continuously from the neural progenitor cells (NPCs) in the subgranular zone (SGZ) throughout life. Both extrinsic signals and intrinsic cellular properties have been identified that dynamically regulate adult hippocampal neurogenesis (Zhao et al., 2008; Ihrie and Alvarez-Buylla, 2011; Ming and Song, 2011). Among these signals and properties, activitydependent regulation by GABA neurotransmission have been shown to influence key steps of hippocampal adult neurogenesis, ranging from progenitor proliferation to newborn neuron maturation and integration (Abrous et al., 2005; Ge et al., 2007; Sernagor et al., 2010). Aberrant neurogenesis has been reported in transgenic mouse models of $\mathrm{AD}$ in which $\mathrm{A} \beta$ and its precursor APP are elevated (Chuang, 2010; Lazarov and Marr, 2010; Winner et al., 2011). As a pathological stimulus, $A \beta$ has been the focus of these studies and the possible confounding effect of overexpression of APP was largely neglected. An understanding of how amyloid pathology and/or APP dysfunction perturb adult hip- 
pocampal neurogenesis in $\mathrm{AD}$ requires delineation of whether and how APP functions as a physiological regulator of neurogenesis, either intrinsically acting through the neural progenitors or extrinsically affecting neurogenic niche. Using genetic loss-offunction studies, we report here that APP plays an important role in regulating GABAergic transmission. Through the control of neuronal inhibition, APP serves as a key physiological regulator of hippocampal neurogenesis.

\section{Materials and Methods}

Mice. All experiments and animal housing were in accordance with procedures approved by the Animal Protocol Committees at Baylor College of Medicine, according to the National and Institutional Guidelines for Animal Care established by the National Institute of Health. Both female and male mice were used in this study. vGAT KO mice and NEX KO mice were generated by crossing homozygous vGAT-Cre knockin mice (Chao et al., 2010) and NEX-Cre knockin mice (Goebbels et al., 2006) with conditional APP knock-out mice (APP f/f), which have been described previously (Wang et al., 2009). Nestin-CreER mice were obtained from The Jackson Laboratory (line number: 016261).

Immunofluorescence. Brains were harvested, postfixed in 4\% paraformaldehyde, dehydrated with $30 \%$ sucrose in PBS, and serially sectioned at $40 \mu \mathrm{m}$. For tamoxifen administration, the mice received daily injections of tamoxifen (125 mg/kg; Sigma) for $10 \mathrm{~d}$. To label proliferating neurons, 4- to 6-month-old mice were treated with $100 \mathrm{mg}$ of BrdU (Sigma-Aldrich) per kg of body weight by intraperitoneal injection for 4 consecutive days. For immunofluorescence and BrdU labeling, sections were incubated in $2 \mathrm{~N}$ hydrochloric acid for $30 \mathrm{~min}$ at $37^{\circ} \mathrm{C}$, followed by neutralization with $100 \mathrm{~mm}$ sodium borate, $\mathrm{pH} 8.5$, for $10 \mathrm{~min}$ at room temperature. Sections were then permeabilized in $0.1 \%$ Triton X-100 (in PBS) for 10 min and blocked with $10 \%$ normal goat serum in $0.1 \%$ Triton X-100 (in PBS; blocking solution) for $1 \mathrm{~h}$ at room temperature. Sections were incubated with primary antibodies in blocking solution overnight at $4^{\circ} \mathrm{C}$. Primary antibodies were as follows: BrdU (Abcam), NeuN (Millipore), doublecortin (DCX; Santa Cruz Biotechnology), Reelin (GE Healthcare), parvalbumin (Millipore), SOX2 (Abcam), GAD-67 (Millipore), and APP Y188 (Epitomics). Sections were then washed and incubated with Alexa Fluor 488- or Alexa Fluor 596-conjugated secondary antibody (Invitrogen) for $1 \mathrm{~h}$ at room temperature. After washing with PBS, sections were mounted with Vectashield Mounting Medium with DAPI (Vector Laboratories). Representative images were acquired using a Leica confocal microscope. Quantification of labeled cells and dendrites was performed with ImageJ software (NIH).

Primary neurosphere culture. One-month-old C57BL/6 wild-type mice were sacrificed and the hippocampi were dissected and diced with a sterile scalpel. Tissue pieces were collected in a mixture of papain and DNases in EBSS and incubated at $37^{\circ} \mathrm{C}$ for $40 \mathrm{~min}$. Then, tissue pieces were pelleted by centrifugation and dissociated to a single-cell suspension, and cells were plated in DMEM/F12 (Invitrogen) supplemented with B27, N2 (Gibco), glucose (Sigma-Aldrich), Na Pyruvate (SigmaAldrich), HEPES (Sigma-Aldrich), L-glutamine (Invitrogen), penicillin/ streptomycin (Invitrogen), heparin (Sigma-Aldrich), EGF (Invitrogen), and bFGF (Sigma-Aldrich) and passaged after $10 \mathrm{~d}$. To evaluate proliferation, cells from dissociated neurospheres were plated and grown in EGF-containing medium $(2 \mathrm{ng} / \mathrm{ml})$ for $4 \mathrm{~d}$. Cells were rinsed three times in fresh medium and cultured for $15 \mathrm{~h}$ in medium with EGF $(2 \mathrm{ng} / \mathrm{ml})$ and $\mathrm{BrdU}(1 \mathrm{~mm})$ diluted to a concentration of $1.5 \mathrm{mg} / \mathrm{ml}$. Cells were fixed and processed for BrdU and SOX2 immunocytochemistry.

Retroviral preparation, stereotactic injection, and confocal imaging anal$y$ sis. A replication-deficient retroviral vector was used to express enhanced GFP driven by a CAG promoter (Zhao et al., 2006). Retroviral particles were generated by cotransfection of three separate plasmids containing the capside (CMV-vsvg), viral proteins (CMV-gag/pol), and transgene (CAG-GFP) onto 293T cells followed by ultracentrifugation of viral supernatant as previously described (Tashiro et al., 2006). For the stereotactic injection, mice were anesthetized and injected with $3 \mu \mathrm{l}$ of CAG-GFP retrovirus into the left and right dentate gyrus. The coordinates from bregma were as follows (in $\mathrm{mm}$ ): 1.9 posterior, 1.5 mediolat- eral, and 2.3 ventral from dura. Animals were sacrificed 4 weeks post injection for morphological analysis. For morphological characterization of the dendritic structure of newborn neurons, 3D reconstruction images of the dendritic trees of GFP-positive neuron were obtained from $Z$-series stacks of confocal images. The projection images were traced with NIH ImageJ using the NeuronJ plugin and subsequently analyzed for the total dendritic length and branch number of each individual GFP-positive neuron in the granule cell layer. Sholl analysis was performed by Sholl Analysis Plugin using a $10 \mu \mathrm{m}$ interval between concentric circles.

Electrophysiology. For whole-cell patch-clamp experiments, hippocampal slices (350 $\mu \mathrm{m}$ thick) were cut using a vibratome (Leica VT1000S) in ice-cold cutting solution containing the following (in $\mathrm{mm}$ ): $92 \mathrm{NaCl}, 2.5 \mathrm{KCl}, 1.2 \mathrm{NaH}_{2} \mathrm{PO}_{4}, 30 \mathrm{NaHCO}_{3}, 20$ HEPES, 25 glucose, 5 ascorbic acid, 2 thiourea, 3 sodium pyruvate, $12 \mathrm{~N}$-acetyl-L-cysteine, 10 $\mathrm{MgSO}_{4} \cdot 7 \mathrm{H}_{2} \mathrm{O}$, and $0.5 \mathrm{CaCl}_{2} \cdot 2 \mathrm{H}_{2} \mathrm{O}$. Slices were incubated for $30 \mathrm{~min}$ in Tris-HEPES recovery solution containing the following (in $\mathrm{mM}$ ): 76 Tris $\mathrm{HCl}, 20$ Tris base, $2.5 \mathrm{KCl}, 1.2 \mathrm{NaH}_{2} \mathrm{PO}_{4}, 30 \mathrm{NaHCO}_{3}, 20$ HEPES, and 25 glucose before being transferred to holding ACSF, which is the same as cutting solution except $\mathrm{Ca}^{2+}$ and $\mathrm{Mg}^{2+}\left(2 \mathrm{~mm} \mathrm{CaCl}_{2} \cdot 2 \mathrm{H}_{2} \mathrm{O}\right.$, and $2 \mathrm{~mm}$ $\mathrm{MgSO}_{4} \cdot 7 \mathrm{H}_{2} \mathrm{O}$ ). One hour after incubation, slices were transferred to a recording chamber perfused with oxygenated standard ACSF (in mM:124 $\mathrm{NaCl}, 2.5 \mathrm{KCl}, 1.2 \mathrm{NaH}_{2} \mathrm{PO}_{4}, 24 \mathrm{NaHCO}_{3}, 5$ HEPES, 12.5 glucose, 2 $\mathrm{MgSO}_{4} 7 \mathrm{H}_{2} \mathrm{O}, 2 \mathrm{CaCl}_{2} .2 \mathrm{H}_{2} \mathrm{O}$ ) containing $1 \mu \mathrm{M}$ TTX, $20 \mu \mathrm{M}$ CNQX, and $50 \mu \mathrm{M}$ D-APV (Tocris Bioscience). Recording temperature was $30 \pm$ $0.5^{\circ} \mathrm{C}$. mEPSCs were recorded using micropipettes with the resistance of 3-6 $\mathrm{M} \Omega$. The recording pipettes were filled with solution containing the following (in mM): $119.5 \mathrm{CsMeSO}_{3}, 15.5 \mathrm{CsCl}, 10 \mathrm{HEPES}, 8 \mathrm{NaCl}, 1$ $\mathrm{MgCl}_{2}, 4 \mathrm{Mg}$-ATP, $0.3 \mathrm{Na}$-GTP, 2.5 Cs-EGTA, $10 \mathrm{TEA}-\mathrm{Cl}$, and $5 \mathrm{QX}-$ $314, \mathrm{pH}$ adjusted to 7.3 with $\mathrm{CsOH}$. mIPSCs and tonic GABAergic current were recorded using the same pipette solution except that $\mathrm{CsMeSO}_{3}$ was replaced with $\mathrm{CsCl}$. Data acquisition was conducted with sampling rates of $20 \mathrm{kHz}$ (mEPSCs) or $10 \mathrm{kHz}$ (mIPSCs and tonic currents) using Multiclamp 700 B amplifier (Axon). Signals were digitized with Digidata $1322 \mathrm{~A}$ (Axon) and filtered at $2 \mathrm{kHz}$ (mEPSCs) or $1 \mathrm{kHz}$ (mIPSCs and tonic currents). mEPSCs and mIPSCs were analyzed using Mini Analysis (Synaptosoft) with an amplitude threshold of $5 \mathrm{pA}$. Tonic GABAergic currents were assessed by measuring the holding current before and after the addition of NO-711 (5 $\mu \mathrm{M}$, Sigma) or bicuculline (20 $\mu \mathrm{M}$; Sigma) and were analyzed with Clampfit 10 .

Contextual discrimination fear conditioning. Mice between 16 and 20 weeks of age were assessed in a contextual discrimination fearconditioning task. This procedure was based on one described previously (Sahay et al., 2011). Mice were trained to discriminate between two contexts through repeated experience in each context. The same identical conditioning chambers $(30 \times 25 \times 25 \mathrm{~cm}$; Med Associates $)$ were used for both shock-associated context A and similar (no shock) context B. The only features that differentiated the two contexts were that the B context had two plastic inserts to cover the walls, a mild vanilla scent as an olfactory cue, and a nonalcoholic antiseptic was used to clean the grids between runs. On each conditioning day, animals were brought to a holding room in their home cages and left undisturbed for a minimum of $30 \mathrm{~min}$. Animals were then transported from the holding room to the conditioning chambers in their home cages. On the first day, the mice were placed only into A, receiving a foot shock of $0.75 \mathrm{~mA}$ after $180 \mathrm{~s}$. Mice were taken out of the chamber $15 \mathrm{~s}$ after termination of the footshock and returned to home cage. On the following day, mice were placed in context A first. After $1 \mathrm{~h}$, mice were placed in the similar context $\mathrm{B}$, in which they were left for $180 \mathrm{~s}$ without shock. Freezing levels were assessed for the first 3 min before shock delivery in training context $A$ and the similar context B each day for 4 additional consecutive days.

Statistical analysis. Data were analyzed by the two-tailed Student's $t$ test and two-way ANOVA followed by Fischer's post hoc test as appropriate. Cumulative frequency of dendritic development was analyzed with Kolmogorov-Smirnov test. Data are presented as mean \pm SEM. Changes were deemed significant if the $p$ value was $<0.05$. Statistical significance is indicated as follows: ${ }^{\star} p<0.05,{ }^{* *} p<0.01$, and ${ }^{\star * *} p<0.001$; n.s. indicates not significant. 
A
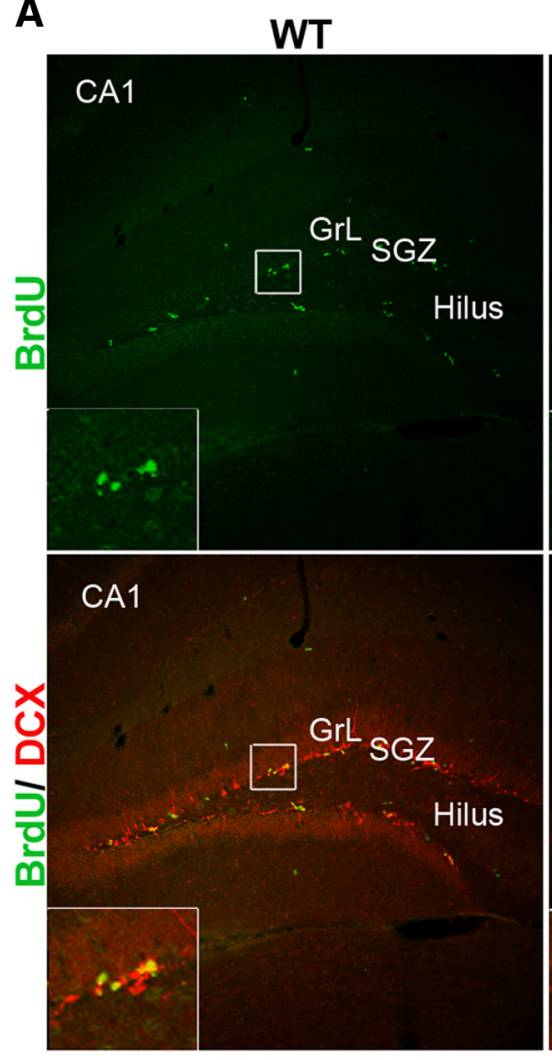

APP-I-

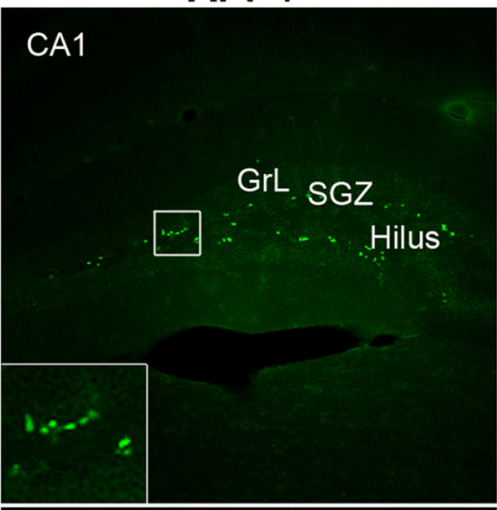

CA1

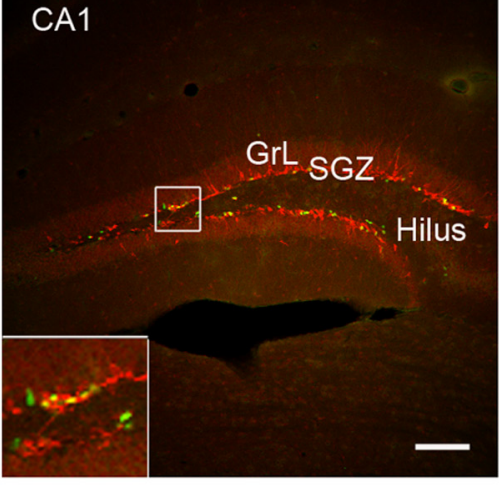

B

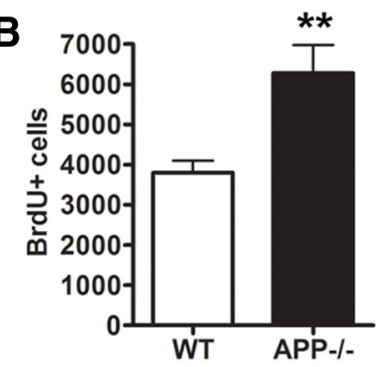

C

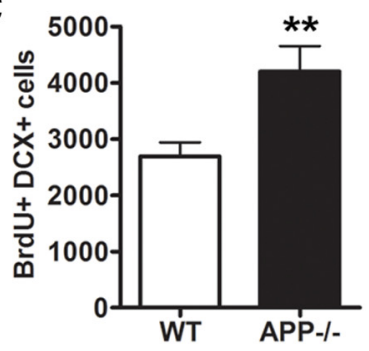

D

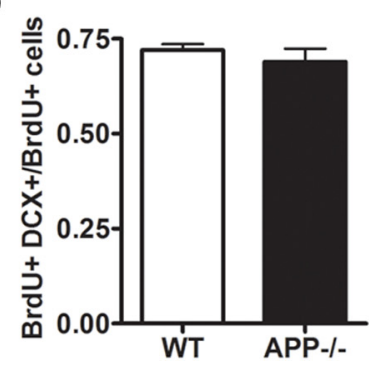

Figure 1. APP deficiency enhances the proliferation of progenitor cells in hippocampal dentate gyrus. $A$, Representative images of double immunohistochemical staining for BrdU (green) and DCX (red) in APP ${ }^{-1-}$ mice and littermate WT controls at 4-6 months old $1 \mathrm{~d}$ after BrdU injection. Area CA1 (CA1), granule cell layer (GrL), sub-granular zone (SGZ), and hilus are as marked. Insets are enlarged view of the bracketed areas. Scale bar, $100 \mu \mathrm{m}$. $\boldsymbol{B}-\boldsymbol{D}$, Quantification of BrdU + cells $(\boldsymbol{B})$ and BrdU/DCX double-positive cells $(\boldsymbol{C})$ of dentate gyrus showed that both were significantly increased in APP ${ }^{-1-}$ mice compared with WT controls. $\boldsymbol{D}$, The ratio of BrdU and DCX double-positive cells/BrdU-positive cells was not significantly different between groups. Error bars indicate SEM. $N=5$ animals per genotype; ${ }^{* *} p<0.01$ (Student's $t$ test).

\section{Results}

$A P P$ deletion leads to enhanced progenitor proliferation and impaired newborn neuron maintenance

Neurogenesis is a multistep process that comprises progenitor cell proliferation, newborn neuron differentiation, maturation, and integration into the pre-existing neuronal circuits. We first asked whether deficiency of APP affected the proliferation of NPCs in the dentate gyrus using 4- to 6-month-old APP knockout mice $\left(\mathrm{APP}^{-/-}\right)$and littermate wild-type controls (WT). To label proliferating cells, we administered BrdU intraperitoneally and analyzed BrdU incorporation $24 \mathrm{~h}$ later. Interestingly, we found significant increases in BrdU-positive cells in the SGZ of $\mathrm{APP}^{-1-}$ mice compared with WT mice (Fig. $1 A, B$ ). In addition, double immunostaining of brain sections with BrdU and DCX, a marker for neural blast/immature neurons, revealed an increased number of cells positive for BrdU and DCX in APP ${ }^{-1-}$ mice (Fig. $1 C)$; the ratio of BrdU and DCX double-positive cells to total BrdU is similar compared with WT controls (Fig. 1D), indicating that the early differentiation of NPCs into immature neurons was not affected by APP deletion, and APP negatively regulates neural progenitor cell proliferation in the SGZ.

We next evaluated the differentiation of NPCs and the maintenance of newborn neurons by injecting 4- to 6-month-old $\mathrm{APP}^{-1-}$ mice and littermate controls with BrdU and examined the BrdU- and neuronal-specific nuclear protein (NeuN)positive cells (BrdU $+/ \mathrm{NeuN}+$ ) 4 weeks and 10 weeks post injection (wpi; Fig. 2) Double labeling of brain sections at 4 wpi with
anti-BrdU and anti-NeuN antibodies revealed a 50\% increase in BrdU-positive and BrdU/NeuN double-positive cells in the $\mathrm{APP}^{-I-}$ mice as compared with WT controls (Fig. 2A-C). Consistent with that of BrdU and DCX staining, the ratio of BrdU+/ $\mathrm{NeuN}+$ cells to total BrdU+ cells was not different between the two groups (Fig. 2D), indicative of normal differentiation of DCX-positive neuroblasts into mature neurons. However, in contrast to the 4 week BrdU retention result, BrdU retention analysis of 10 wpi mice revealed that, although the absolute number of BrdU + cells was still higher in APP-null mice (Fig. $2 F$ ), the $\mathrm{BrdU} / \mathrm{NeuN}$ double-positive neurons were comparable between the two groups (Fig. $2 G$ ), resulting in the significantly lower ratio of BrdU $+/ \mathrm{NeuN}+$ cells to total BrdU-positive cells in $\mathrm{APP}^{-/-}$ mice compared with that of WT controls (Fig. $2 \mathrm{H}$ ). These data provide strong support for a critical role of APP in the maintenance of newly produced neurons in the hippocampal dentate gyrus without affecting newborn neuron differentiation.

\section{APP regulates dendritic development of adult-born neurons}

Reduced adult-born neurons at later stages indicate that the morphology and/or function in these neurons may be abnormal without APP. We thus examined the dendritic morphology of the adult-born neurons by stereotaxically injecting a retroviral vector encoding RFP (retro RFP) into the dorsal hippocampus of 2- to 4-month-old mice followed by measurements of total dendritic length and branching at 4 wpi. RFP + cells in WT mice were located in the granule cell layer (GrL) and had a well developed 


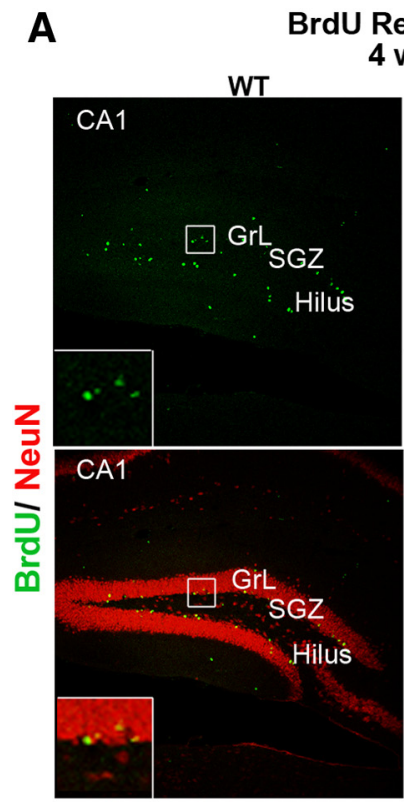

B

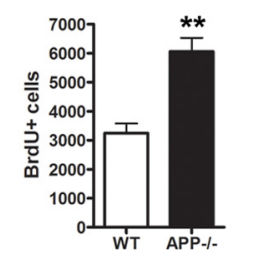

I

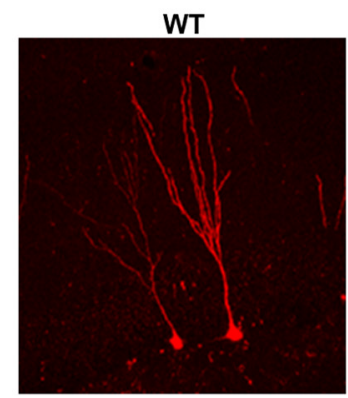

L

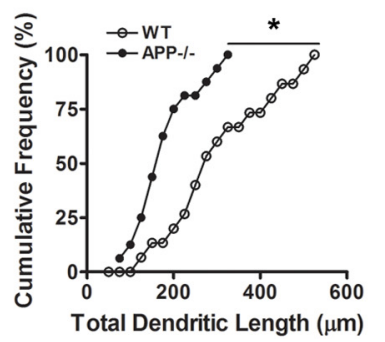

C

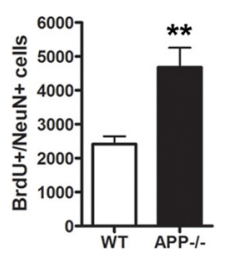

D

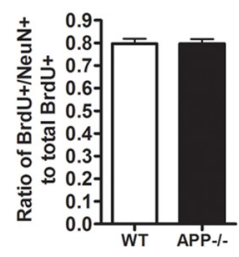

APP-I-

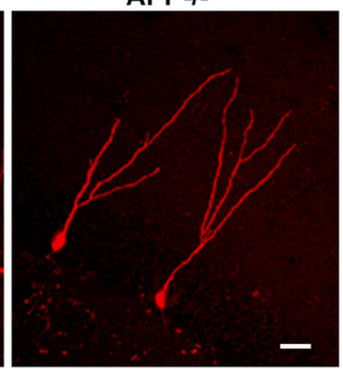

M

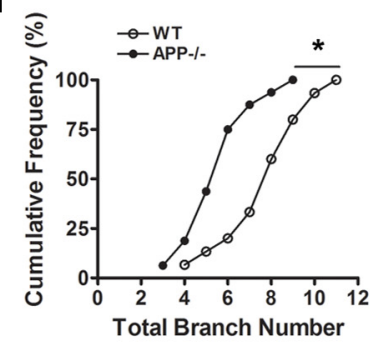

F

J
E
BrdU Retention

10 wpi

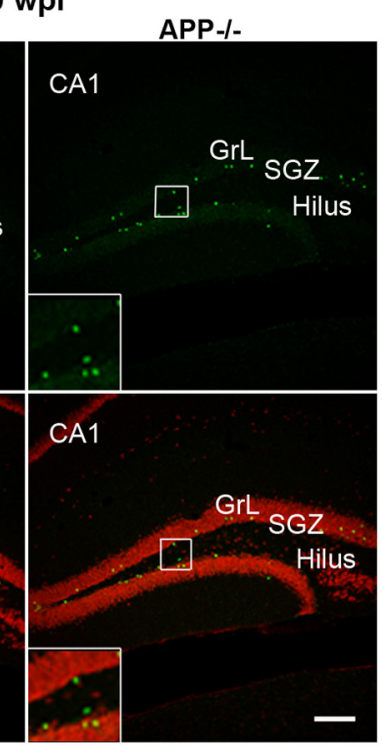

G

H
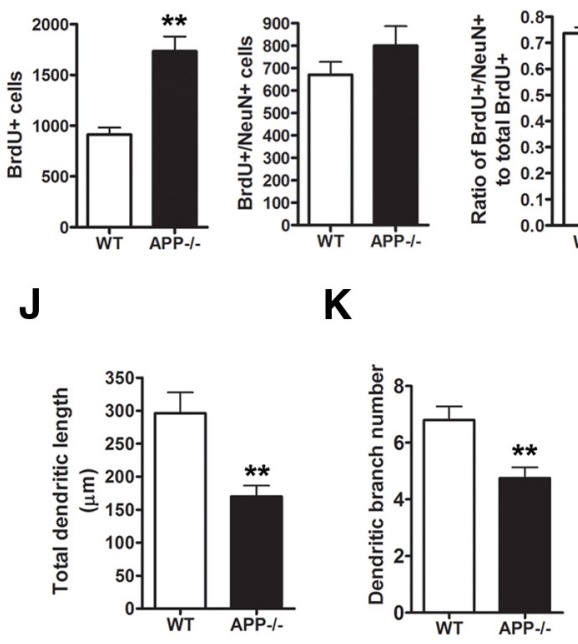

N
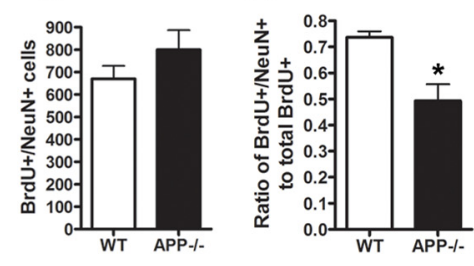

K

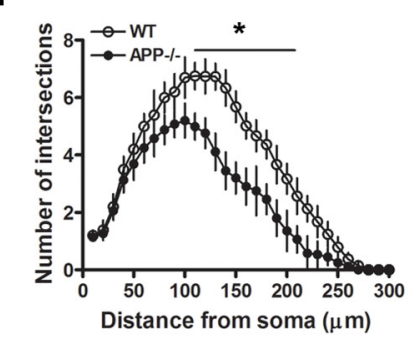

Figure 2. APP deficiency reduces the survival of newborn neurons. $\boldsymbol{A}, \boldsymbol{E}$, Representative images of double immunohistochemical staining for BrdU (green) and NeuN (red) 4 weeks ( $\boldsymbol{A}$ ) and 10 weeks $(\boldsymbol{E})$ after the last administration of BrdU in APP ${ }^{-1-}$ mice and littermate WT controls at $4-6$ months old. Area CA1 (CA1), GrL, SGZ, and hilus are as marked. Insets are enlarged view of the bracketed areas. Scale bars: $100 \mu \mathrm{m}$. $\boldsymbol{B}-\boldsymbol{D}$, Quantification of BrdU + cells $(\boldsymbol{B})$, BrdU/NeuN double-positive cells $(\boldsymbol{C})$, and the ratio of BrdU and NeuN double-positive cells/BrdU-positive cells $(\boldsymbol{D})$ in WT and APP ${ }^{-I-}$ mice 4 weeks after BrdU injection. $\boldsymbol{F}-\boldsymbol{H}$, Quantification of BrdU + cells $(\boldsymbol{F}), \operatorname{BrdU} /$ NeuN double-positive cells $(\boldsymbol{G})$, and the ratio of BrdU and NeuN double-positive cells/BrdU-positive cells $(\boldsymbol{H})$ in WT and APP ${ }^{-I-}$ mice 10 weeks after BrdU injection. Error bars indicate SEM. $N=5-6$ animals per genotype; ${ }^{*} p<0.05,{ }^{* *} p<0.01$ (Student's $t$ test). $\boldsymbol{I}-\boldsymbol{N}$, APP regulates dendritic development of adult-born neurons. $I$, Confocal 3 D reconstruction of dendrites of individual retrovirus-RFP + dentate GCs at 4 wpi in WT and APP ${ }^{-I-}$ mice. Scale bar, $20 \mu \mathrm{m}$. J-K, Quantification of total dendritic length $(\boldsymbol{J})$ and branch numbers $(\boldsymbol{K})$ of newborn neurons at 4 wpi in WT and APP ${ }^{-1-}$ mice. Values represent mean \pm SEM, ${ }^{* *} p<0.01$ ( $t$ test). $L, M$, Cumulative distribution plots of total dendrite length $(\boldsymbol{L})$ and branch numbers $(\boldsymbol{M}){ }^{*} p<0.05$ (Kolmogorov-Smirnov test), $N=16$ from 4 animals per genotype. $N$, Sholl analysis of dendritic complexity of RFP + neurons at 4 wpi. Values represent mean \pm SEM (same groups of neurons as in $L$ ). 
A

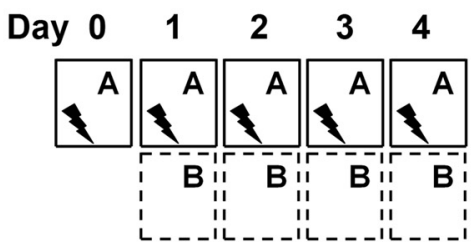

C

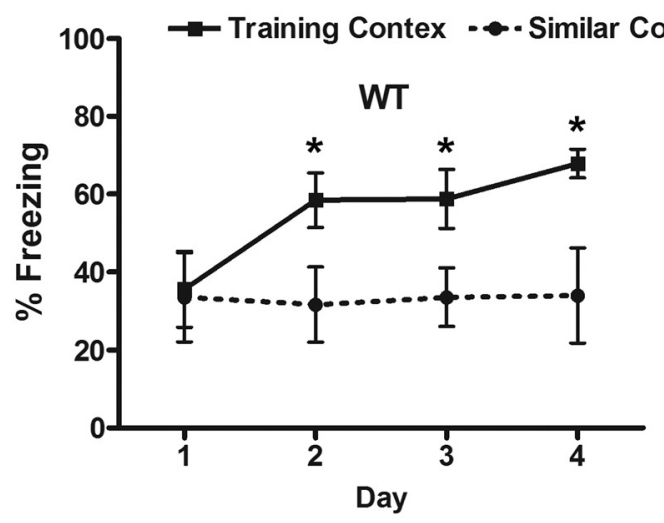

B

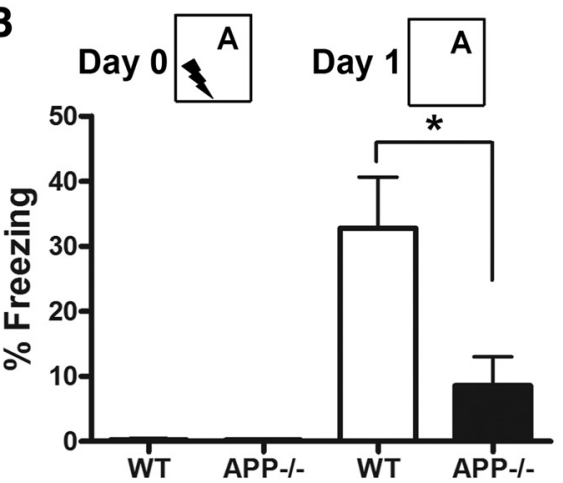

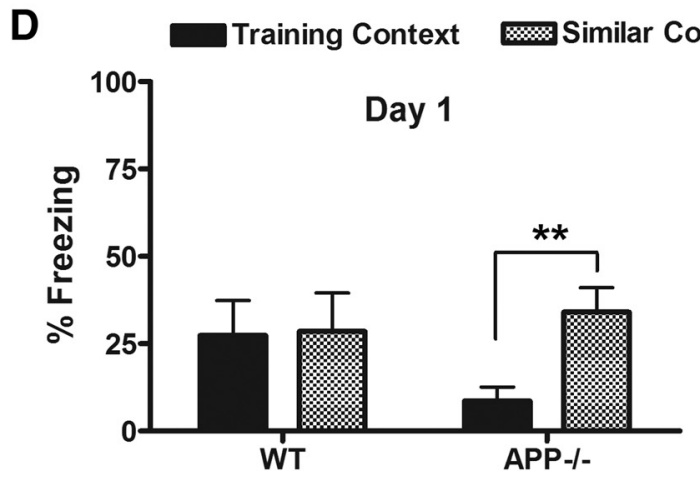
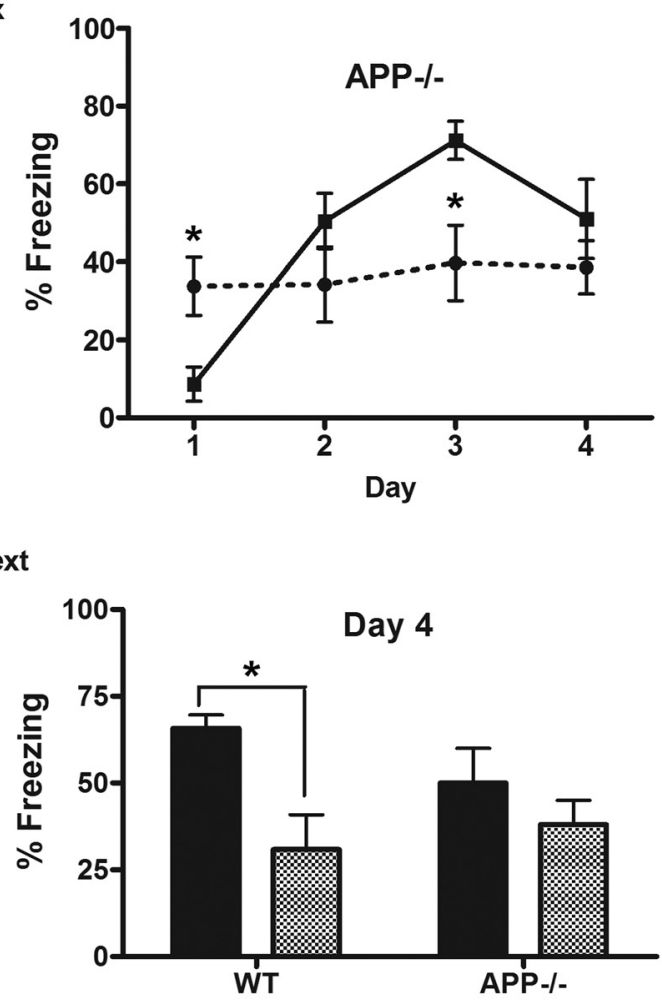

Figure 3. APP deficiency leads to reduced contextual discrimination. $A$, Experimental design to test discrimination between similar contexts A and B in WT and APP ${ }^{-/-}$mice (please see Materials and Methods for detailed information). $\boldsymbol{B}$, All groups showed negligible levels of freezing before a single footshock (Day 0 ). A single $2 \mathrm{~s}$ footshock of $0.75 \mathrm{~mA}$ was delivered at $180 \mathrm{~s}$ after placement of the mouse in the training context A. Twenty-four hours later the mice were placed back to the same training context A and freezing behaviors were recorded. APP ${ }^{-1-}$ mice displayed significantly reduced level of conditioning to training context A compared with WT (Day 1). C, Percentage of freezing of WT and APP ${ }^{-1-}$ mice over $4 \mathrm{~d}$ of the experiment. On day 1, WT mice showed comparable levels of generalization between the two contexts, whereas APP ${ }^{-1-}$ mice displayed reduced freezing in context A. WT mice distinguished between contexts A and B stating on day 2 and lasted to day 4 whereas APP ${ }^{-1-}$ mice distinguished between two contexts only on day $3 ;{ }^{*} p<0.05$ (two-way ANOVA). D, APP ${ }^{-1-}$ mice were unable to discriminate between the two contexts by day 4 of testing. Results are presented as mean \pm SEM. $N=6-10$ for each genotype; ${ }^{*} p<0.05,{ }^{* *} p<0.01$ (Student's $t$ test).

dendritic tree extending deep into the molecular layer, whereas in $\mathrm{APP}^{-1-}$ mice $\mathrm{RFP}+$ cells exhibited a significant reduction in dendritic growth (Fig. $2 I-M$ ). Sholl analysis further revealed a reduction in the dendritic complexity of $\mathrm{APP}^{-1-} \mathrm{RFP}+$ neurons (Fig. 2N). These results demonstrate that APP regulates dendritic development of newborn granule cells.

\section{APP is required for neurogenesis-mediated}

\section{contextual discrimination}

Having established that deletion of $A P P$ results in morphological impairments of adult-born neurons, we reasoned that these deficits could affect hippocampal-dependent behavior. Previous studies have shown that adult hippocampal neurogenesis plays a crucial role in the pattern-separation functions of the dentate gyrus (Treves et al., 2008; Yassa and Stark, 2011), and spatial discrimination tasks such as contextual fear and radial-arm maze have been used to test for a functional role of newborn neurons (Sahay et al., 2011; Nakashiba et al., 2012). We thus subjected the $\mathrm{APP}^{-1-}$ mice to a contextual discrimination fear-conditioning task (Sahay et al., 2011). In this test, mice were subjected to fearconditioning training in which they learned to discriminate a pair of very similar contexts over repeated trials with a single footshock in one of the contexts (training context; A) and no footshock in the other context (similar context; B; Fig. $3 A$ ). In the fear-conditioning paradigm, $\mathrm{APP}^{-1-}$ mice displayed a reduced level of fear memory to context A compared with the control mice (Fig. 3B). During contextual discrimination trainings, WT mice distinguished between contexts $\mathrm{A}$ and $\mathrm{B}$ starting on day 2 


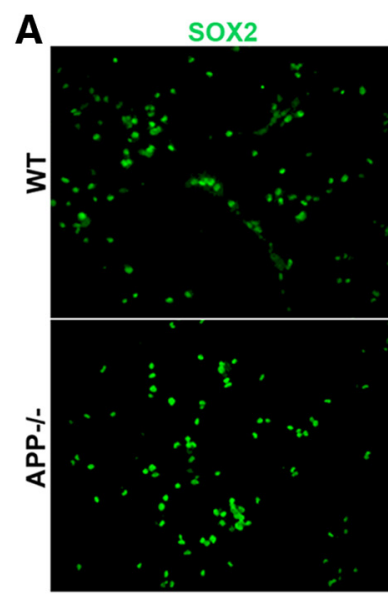

B
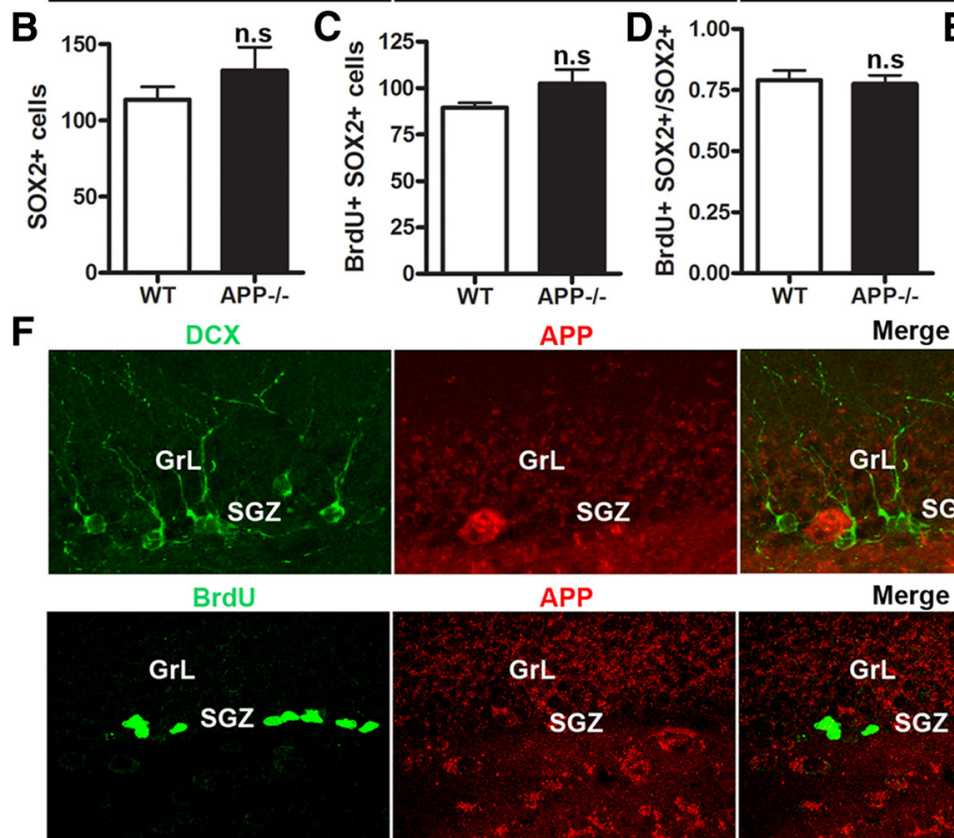

G

Retro RFP

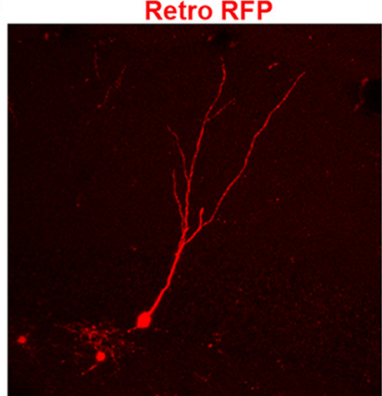

Retro RFPIAPP

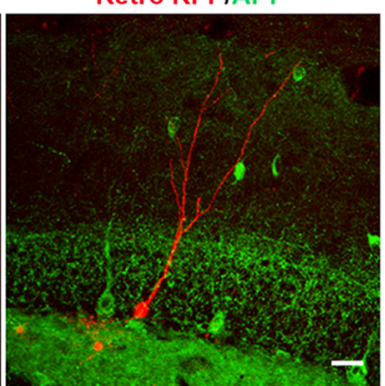

H

Retro RFP / Retro GFP-cre

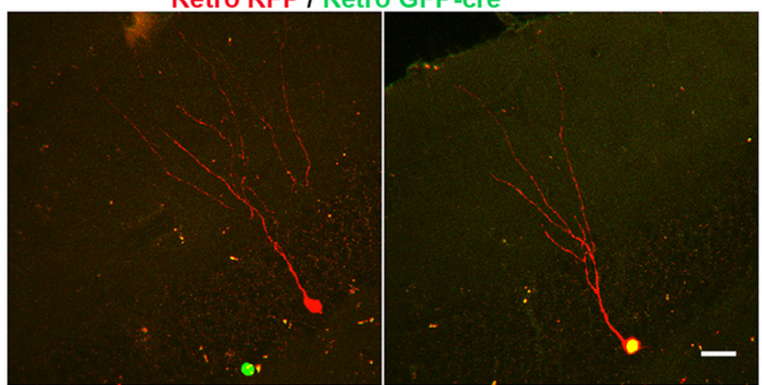

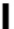

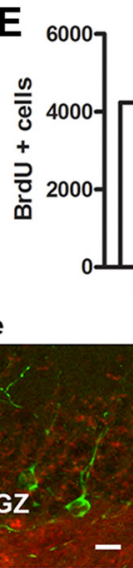

Merge
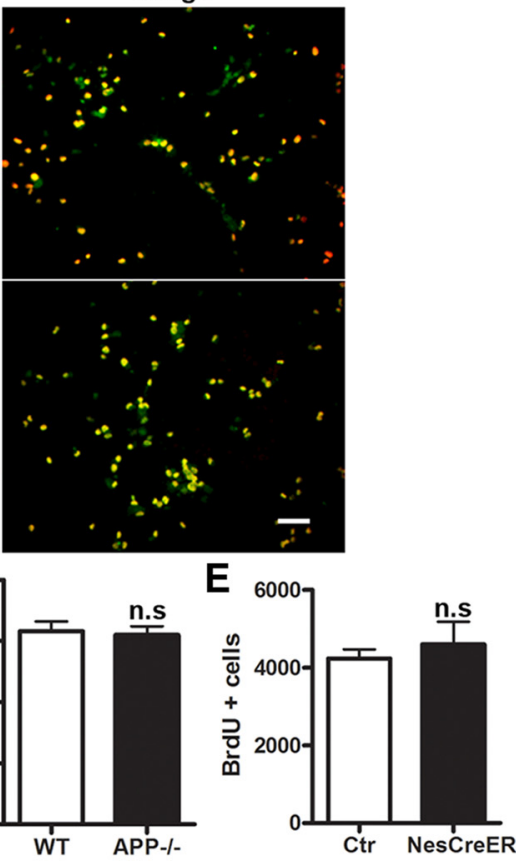

Merge

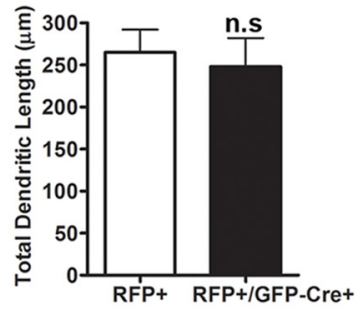

Figure 4. Noncell-autonomous effect of APP on adult hippocampal neurogenesis. A-D, Double labeling of WT and APP ${ }^{-1-}$ neurosphere cultures for SOX2 (green) and BrdU (red; $A$ ) and quantification of $\mathrm{SOX} 2+$ cells $(\boldsymbol{B}), \mathrm{SOX2} / \mathrm{BrdU}$ double-positive cells $(\boldsymbol{C})$, and the ratio of SOX2 + BrdU + to BrdU + cells $(\boldsymbol{D})$ showed similar number of dividing neural progenitor cells in APP $-1-$ cultures and WT controls. Data represents average of three independent experiments. $\boldsymbol{E}$, Quantification of BrdU-positive cells in tamoxifen-treated control and APP f/f; (Figure legend continues.) 
and persisting to day 4 , whereas the $\mathrm{APP}^{-1-}$ mice distinguished between the two contexts only on day 3 (Fig. 3C,D). Thus, loss of APP results in deficits in discrimination of highly similar contexts, consistent with the impaired neurogenesis in these mice.

\section{Noncell-autonomous effects of APP in adult neurogenesis}

To assess whether the impaired adult neurogenesis in APPdeficient mice was mediated by a cell-autonomous mechanism or due to the loss of extrinsic regulation, we first generated neural sphere cultures from WT and $\mathrm{APP}^{-1-}$ hippocampus and measured their proliferation in vitro by BrdU application in the culture and double immunostaining for BrdU and SOX2, a transcription factor expressed in neural stem cells (NSCs). Analysis of the number and percentage of SOX $2+$ and $\mathrm{BrdU}+/$ $\mathrm{SOX} 2+$ cells failed to detect any differences between WT and $\mathrm{APP}^{-1-}$ cultures (Fig. $4 A-D$ ), questioning an intrinsic activity of APP in NSC proliferation. To provide in vivo evidence, we crossed an APP floxed allele (APP f/f; Wang et al., 2009) with Nestin-CreER mice which, upon tamoxifen treatment, results in the NPC-specific deletion of APP. Four-month-old APP f/f; Nestin-CreER mice were injected with BrdU after tamoxifen treatment; subsequent measurement of BrdU incorporation in these mice revealed a similar number of BrdU + cells in APP f/f; Nestin-CreER mice in comparison with Cre-negative control littermates (Fig. 4E). These results combined strongly argue against a cell-autonomous role of APP in NPC proliferation.

To explore the mechanistic basis for the noncell-autonomous effects, we assessed APP expression in cells of the neurogenic niche by BrdU injection followed by double immunostaining of BrdU or DCX with APP, which revealed that, unexpectedly, APP was undetectable in BrdU-positive NPCs and DCX-positive immature neurons (Fig. 4F). This was also the case for mature adult-born neurons as evidenced the lack of APP in retroviralRFP-labeled cells (Fig. 4G). To examine the NPC-specific deletion of APP on dendritic development of the adult-born neurons, we stereotaxically injected a mixture of retroviruses encoding GFP-Cre and mRFP into the hippocampus of $A P P \mathrm{f} / \mathrm{f}$ mice to directly compare newborn neurons carrying the APP deletion (mRFP+/GFP-Cre) with wild-type neurons (mRFP+ only) from the same sections of each animal. Consistent with the lack of APP expression in adult-born neurons and unlike the phenotype observed in the $\mathrm{APP}^{-1-}$ mice, mRFP+/GFP-Cre cells exhibited normal dendritic arborization compared with mRFP+ only neurons (Fig. 4H,I). Therefore, these results provide clear evidence that the effect of APP on NPC proliferation and newborn neuron morphology was not mediated by a cellautonomous mechanism.

\section{$\leftarrow$}

(Figure legend continued.) Nestin-CreERT (NexCreER) mice $1 \mathrm{~d}$ after injection revealed similar progenitor cell proliferation. $\boldsymbol{F}$, Double immunostaining of wild-type mouse brains for $D C X$ (green) and APP Y188 (red; top) or BrdU (green) and APP Y188 (red; bottom) revealed no detectable expression of APP in DCX + or BrdU + cells. GrL and SGZ are as marked. G, Retroviral RFP injection followed by APP immunostaining at 4 wpi did not reveal detectable APP expression (APP, green) in RFP + newborn neurons (retro RFP, red) in wild-type mice. $\boldsymbol{H}$, Confocal 3D reconstructed images of APP $\mathrm{f} / \mathrm{f}$ mice coinjected with retroviral RFP (red) and GFP-Cre (green) showing an APP-containing newborn neuron infected with retroviral RFP alone (left) or APP-deleted newborn neuron infected with both retro RFP and GFP-Cre (right) at 4 wpi. I, Quantification of dendritic length of newborn neurons with (RFP +) or without APP (RFP+/GFP-Cre +). Values represent mean \pm SEM. Scale bars: $\boldsymbol{A}, 50 \mu \mathrm{m} ; \boldsymbol{F}, 10 \mu \mathrm{m} ; \boldsymbol{G}, \boldsymbol{H}, 20 \mu \mathrm{m} . \boldsymbol{N}=4-5$ animals per genotype; n.s: nonsignificant (Student's test).

\section{High levels of APP expression in GABAergic neurons of adult hippocampus}

It is known that proliferation of neural progenitors and subsequent maturation and survival depends on a host of environmental and cellular factors (Ming and Song, 2011). In particular, recent studies have demonstrated that tonic inhibition, originating from parvalbumin- or Reelin-positive hilar interneurons, critically influences dentate gyrus neural progenitor proliferation and subsequent development (Tozuka et al., 2005; Ge et al., 2006; Song et al., 2012). Our preceding analysis supports a noncellautonomous role of APP in mediating hippocampal adult neurogenesis. Hence, the question arises whether impaired neurogenesis observed in $\mathrm{APP}^{-1-}$ mice was attributed to impairments in GABAergic transmission.

APP has been shown to be highly expressed in the brain during developmental stages and is expressed throughout the mouse brain in adulthood, though the level and pattern of expression in each neuronal subtype have not been defined. Our previous study identified a highly specific rabbit monoclonal antibody against APP (Y188) and showed that localization of APP is restricted to cells of neuronal lineages (Guo et al., 2012). To gain further insight into the noncell-autonomous role of APP on neurogenesis, we performed an in-depth analysis of APP expression in the adult mouse brain using 2- to 4-month-old WT mice. We found that, in the hippocampus, the pyramidal cell layer of CA1-CA3 subfields showed intense APP staining while minimal immunostaining was detected in the granule cell layer of the dentate gyrus (Fig. $5 A$ ). In contrast, cells that were strongly immunoreactive for APP in the dentate gyrus showed a pattern of scattered distribution in the hilus and molecular layer, reminiscent of GABAergic interneurons. Since dentate granule cells (GCs) receive inhibitory inputs from a variety of GABAergic interneurons, we characterized the subtype of APP-expressing GABAergic interneurons by double labeling using specific markers for parvalbumin-positive basket cells (PV) or Reelin-expressing interneurons. Our results showed that almost all of these cells were intensely immunoreactive for APP (Fig. 5B,C). The finding of high levels of APP expression in specific subpopulation of GABAergic neurons, in particular neurons that are critical for neurogenesis, suggests that APP may affect neurogenesis through regulation of GABAergic inhibition.

\section{APP regulates GABAergic tone and GABAergic synaptic transmission to dentate granule neurons}

The presence of high levels of APP in GABAergic interneurons prompted us to test whether APP mediates GABAergic signaling in the adult brain. To determine the level of tonic inhibition in dentate GCs of $\mathrm{APP}^{-1-}$ mice, we recorded GABAergic currents from visually identified GCs of 3-week-old mice in the presence of ionotropic glutamate receptor antagonists. After achieving stable recordings under control conditions in ACSF, $\mathrm{GABA}_{\mathrm{A}} \mathrm{R}$ antagonist bicuculline was added to block phasic GABAergic currents. Upon application of bicuculline, tonic inhibition was blocked and the GC holding current significantly shifted to more positive values (Fig. $5 D$ ). We determined the tonic GABAergic current amplitude by subtracting the holding current in ACSF from the holding current in the presence of bicuculline. We found that the average amplitude of tonic currents was significantly smaller in APP ${ }^{-1-}$ mice as compared with WT controls (Fig. $5 D, E$ ), demonstrating that APP is required for tonic GABA inhibition in mature dentate granule neurons. Since the level of tonic GABA inhibition is determined by ambient GABA concentration, which in turn is influenced by the balance between GABA 


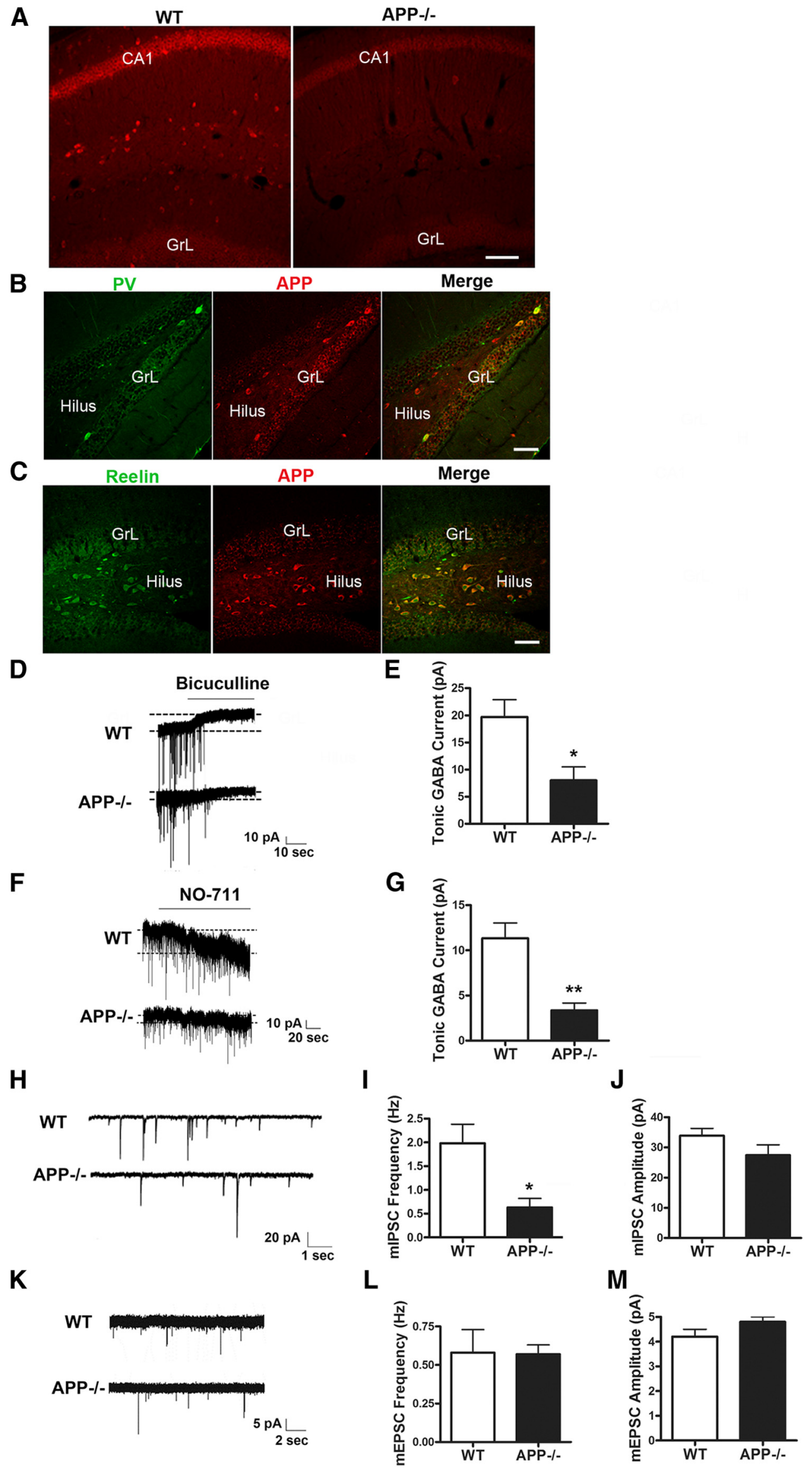


release and GABA uptake, to further dissect out the mechanism of reduced tonic inhibition in $\mathrm{APP}^{-1-}$ mice, we performed dentate GC recordings in the presence of NO-711, a GABA transporter GAT-1-specific blocker. Application of NO-711 elicited an inward current, reflecting accumulation of GABA in the extracellular space (Fig. 5F). NO-711-evoked currents were significantly smaller in GCs from $\mathrm{APP}^{-1-}$ mice than from WT mice (Fig. $5 F, G$ ), demonstrating a reduction of ambient GABA release from GABAergic interneurons of $\mathrm{APP}^{-1-}$ mice that leads to the decreased tonic GABAergic function in these mice.

We next examined GABA-mediated synaptic transmission by recording mIPSCs in dentate granule neurons in the presence of CNQX, D-APV, and TTX. We observed that the frequency of mIPSCs recorded from dentate GCs was significantly decreased in $\mathrm{APP}^{-1-}$ mice relative to the controls, while the mIPSC amplitudes were not significantly different (Fig. $5 H-J$ ). We next measured the frequency and amplitude of mEPSC of GCs of $\mathrm{APP}^{-1-}$ and control mice. In contrast to that of mIPSCs, the frequency and amplitude of mEPSCs were similar in $\mathrm{APP}^{-1-}$ and control mice (Fig. $5 K-M$ ). The decreased mIPSC frequency in GCs indicates a reduction in the number of functional GABAergic synapses onto the GCs and/or reduced presynaptic GABA release in the absence of APP. Given the role of APP in promoting synapse formation (Wang et al., 2009), these results indicate that reduced GABA-mediated synaptic transmission in $\mathrm{APP}^{-/-}$mice is due to defects in the formation of GABA-mediated synapses and thus implicate a specific role of APP in regulating GABAergic input to GCs.

\section{Selective deletion of APP in GABAergic neurons leads to impaired neurogenesis}

To directly delineate a functional role of GABAergic APP in adult neurogenesis, we crossed the $A P P \mathrm{f} / \mathrm{f}$ allele with either the vGAT-Cre (Chao et al., 2010) or NEX-Cre (Goebbels et al., 2006) drivers, which leads to the specific deletion of APP in GABAergic (vGAT KO) or glutamatergic (NEX KO) neurons, respectively, starting from E11.5 and persisting throughout adulthood. Immunofluorescence staining of 4-month-old brains confirmed the deletion of APP in GABAergic neurons in the vGAT KO mice and in excitatory, glutamatergic principal neurons in the NEX KO mice, respectively (Fig. 6A). To investigate the role of APP in

\section{$\leftarrow$}

Figure 5. APP regulation of GABAergic tone and GABAergic synaptic transmission to dentate granule neurons. A-C, APP expression in GABAergic neurons of adult hippocampus. A, APP staining using the $Y 188$ antibody showing abundant expression in CA1 pyramidal neurons and hilar interneurons in 4-month-old WT mice. APP ${ }^{-1-}$ is used as a negative control. B, C, Confocal images of double immunostaining for PV $(\boldsymbol{B})$ or Reelin ( $(\boldsymbol{)}$ with APP revealing APP expression in both types of GABAergic interneurons in the hilus. CA1, GrL, and hilus regions are as marked. Sale bars: $50 \mu \mathrm{m}$. $\boldsymbol{D}$, Representative current traces from dentate GCs in brain slices of WT and APP ${ }^{-1-}$ mice. Application of the $G A B A_{A}$ antagonist bicuculline reveals a tonic conductance. $\boldsymbol{E}$, Average tonic currents in APP ${ }^{-1-}$ GCs are lower than in WT cells as revealed by bicuculline application. $\boldsymbol{F}$, Representative traces recorded in $\mathrm{GCs}$ from WT and APP ${ }^{-1-}$ mice, illustrating the effect of GABA uptake inhibition in the two genotypes. Blocking GABA uptake with the GAT-1 inhibitor N0-711 results in accumulation of GABA in the extracellular space and activation of tonic conductance. $\mathbf{G}$, N0-711-evoked currents were on average smaller in APP $^{-/-}$GCs compared with in WT cells. $\boldsymbol{H}$, Examples of mIPSC recordings obtained from GCs of WT and APP ${ }^{-I-}$ mice. I, mIPSC frequency is significantly reduced in dentate gyrus slices from $\mathrm{APP}^{-I-}$ mice compared with controls. J, No change in mIPSC amplitude was observed in $\mathrm{APP}^{-1-}$ mice. $\boldsymbol{K}$, Representative traces of mEPSCs recorded from GCS of WT and APP ${ }^{-1-}$ mice. mEPSC frequency $(\boldsymbol{L})$ and amplitude $(\boldsymbol{M})$ were similar between WT and APP ${ }^{-1-}$ mice. Data represent mean \pm SEM. $N=7-9$ slices from at least 5 animals per genotype; ${ }^{*} p<0.05$, ${ }^{* *} p<0.01$ by Student's $t$ test.
GABAergic interneurons in adult neurogenesis, we performed the same BrdU labeling and retroviral-GFP injection experiments in the 4-month-old subtype-specific APP mutants. We observed significantly more proliferating $\mathrm{BrdU}+$ cells in the dentate gyrus of vGAT KO mice than the littermate controls $1 \mathrm{~d}$ after BrdU injection (Fig. 6B,C). In contrast, NEX KO mice displayed similar proliferative activity compared with the controls (Fig. $6 B, C$ ). Analysis of dendritic arborization in vGAT KO and NEX KO mice revealed that the total dendritic length of RFP + neurons was significantly reduced in vGAT KO mice whereas in NEX KO mice it was similar compared with the control mice (Fig. $6 D, E$ ). To determine whether the neurogenesis deficits of the vGAT KO mice were the result of impaired GABAergic function, we performed electrophysiological recordings of mIPSCs on hippocampal slices of vGAT KO mice. Similar to the germline APP deletion, inactivation of $A P P$ in GABAergic neurons resulted in reduced mIPSC frequency, whereas the mIPSC amplitudes were not significantly different (Fig. $6 F-H$ ). We then subjected the vGAT KO and littermate control mice to a contextual discrimination fearconditioning task described above. In the fear-conditioning paradigm, vGAT KO mice displayed a similar level of fear memory to context A compared with the control mice (Fig. 6I). During contextual discrimination trainings, control mice distinguished between contexts A and B starting on day 4, whereas the vGAT KO mice failed to distinguish between the two contexts (Fig. 6J). Thus, loss of GABAergic APP results in deficits in discrimination of highly similar contexts, consistent with the impaired neurogenesis in these mice.

These results demonstrate that APP expressed in GABAergic, but not glutamatergic, neurons controls different processes of adult hippocampal neurogenesis through the regulation of GABAergic interneuron functions.

\section{Discussion}

In this study we investigated the role of APP in adult hippocampal neurogenesis. Using genetic loss-of-function models along with retroviral reporters and through a combination of morphological, electrophysiological, and behavioral approaches, we identified a crucial role of APP in regulating multiple steps of adult neurogenesis, including progenitor cell proliferation and newborn neuron maturation. Our elucidation of the noncellautonomous origin of the neurogenic deficits unveiled a novel function of APP in regulating tonic and phasic GABAergic transmission. At the functional level, we provide evidence that GABAergic APP, possibly through the regulation of adult hippocampal neurogenesis, controls a mouse's cognitive ability to discriminate between similar contexts. Our findings not only reveal novel and intriguing insights into APP's physiological function, it may also have implications to $\mathrm{AD}$ pathogenesis. In particular, in addition to generating neurotoxic $\mathrm{A} \beta$ through proteolytic processing, deregulation of APP could contribute to AD through compromised adult hippocampal neurogenesis and hippocampal-dependent behavior. Furthermore, APP dysfunction leads to the deficit in GABAergic synaptic transmission, which may contribute or exacerbate disturbed network excitability observed in $\mathrm{AD}$.

\section{APP as an extrinsic physiological regulator of hippocampal neurogenesis}

A role of APP in adult neurogenesis was previously reported by showing that application of $\mathrm{AAPP} \alpha$ promotes the proliferation of neural progenitor cells in subventricular zone in vivo (Caillé et al., 2004) or in neural sphere cultures in vitro (Caillé et al., 2004; 

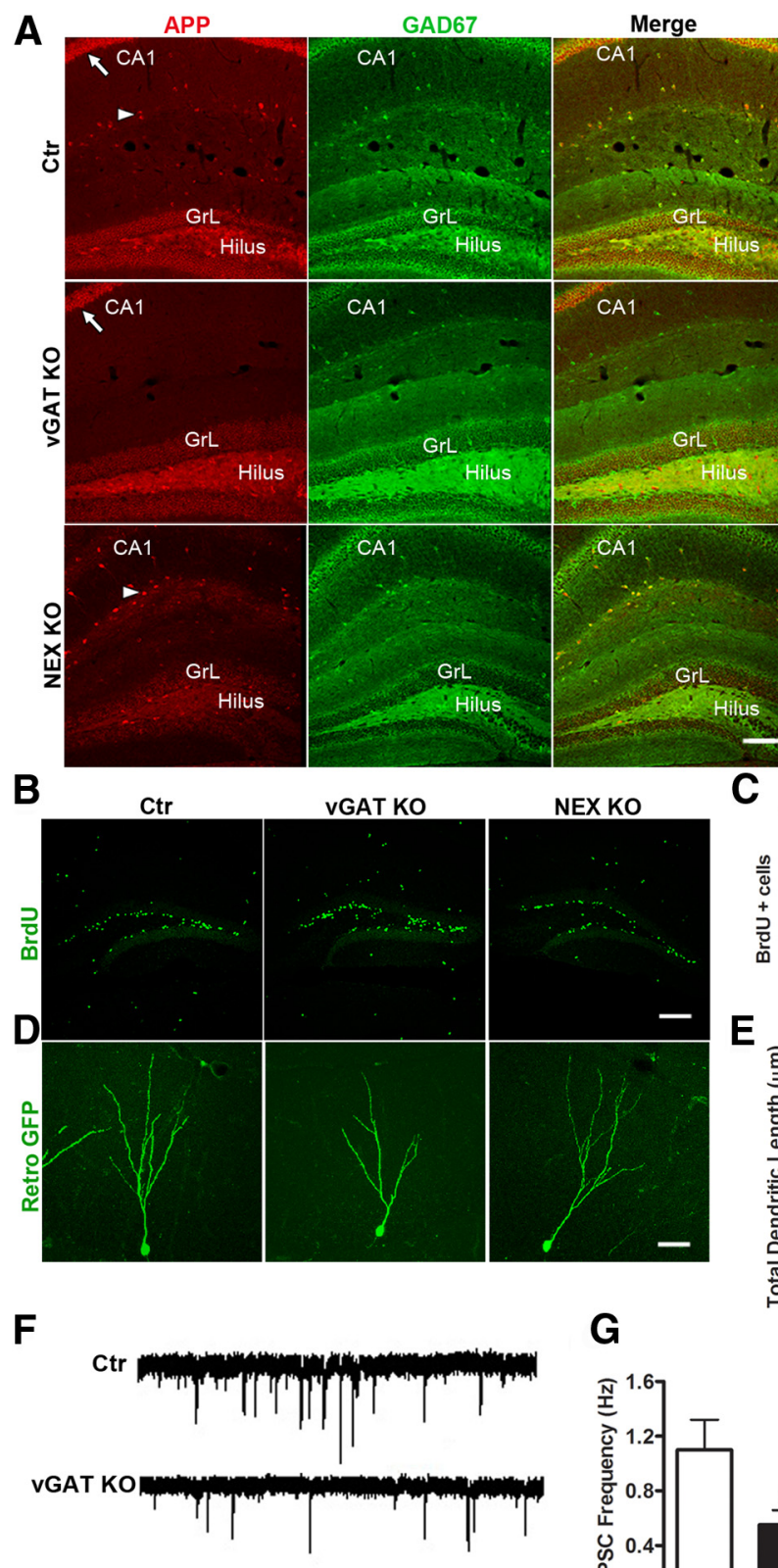

G
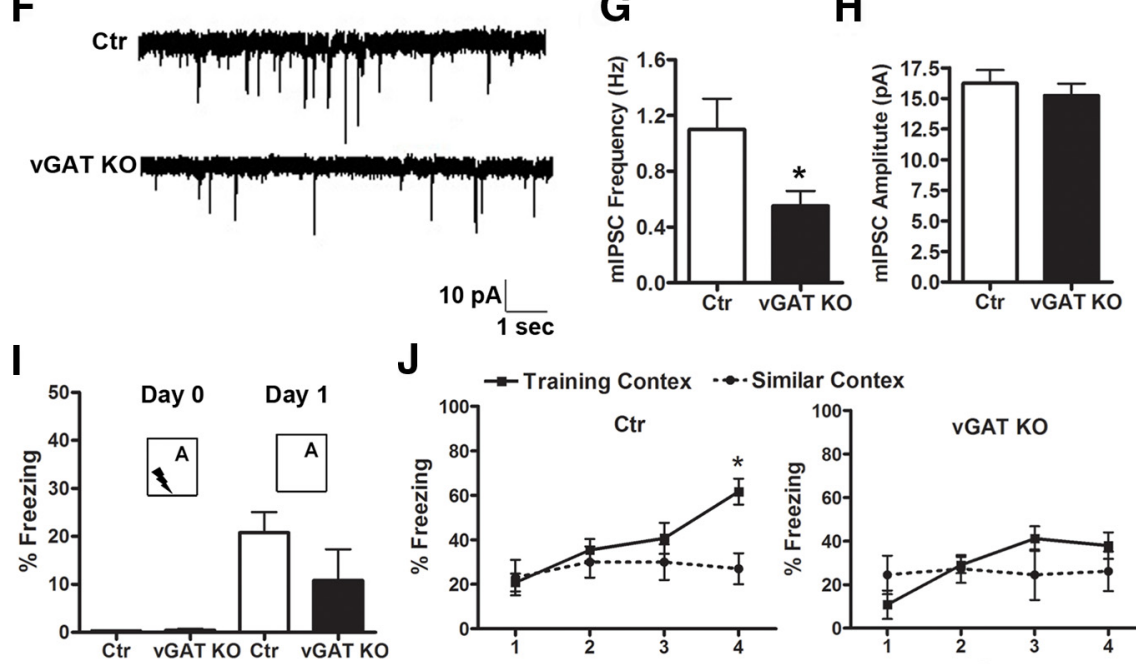

J $1 \mathrm{sec}$
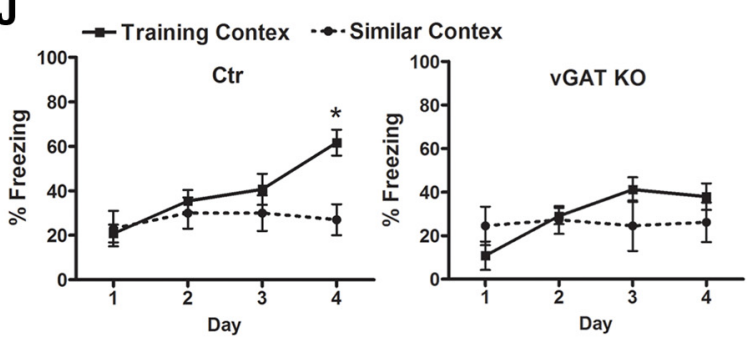

Figure 6. Selective deletion of APP in GABAergic interneuron impairs neurogenesis. $A, A P P$ and GAD-67 double immunostaining showing APP expression in both GAD-67-positive GABAergic interneurons (arrowhead) and CA1 pyramidal neurons (arrow) of control mice (Ctr), lack of APP expression in GABAergic interneurons but not CA1 pyramidal neurons in APPf/f; vGAT-Cre (vGAT K0) mice, and absence of expression in CA1 but not GABAergic neurons in APP f/f; NEX-Cre (NEX KO) mice. GrL and hilus region are as marked. $\boldsymbol{B}$, Representative images of BrdU incorporation in Ctr, vGAT KO, and NEX KO mice. $\boldsymbol{C}$, Quantification of $\boldsymbol{B}$ revealing increased progenitor cell proliferation in the SGZ of vGAT KO mice but not in NEX KO mice. $N=4 / 5$ for each genotypes. As no significant difference was detected between the controls from littermates of vGAT KO and NEX KO mice, the values of two groups of controls were pooled and expressed as single value (Ctr). Student's $t$ tests were performed comparing values from vGAT KO and NEX KO mice to their littermate controls; ${ }^{*} p<0.05$. D, Representative images of reconstructed newborn neurons in GrL with
Demars et al., 2011). However, several key questions remain unresolved. First, these studies use exogenously added APP and thus do not address a physiological function of APP. Second, whether APP regulates hippocampal neurogenesis in vivo, which is implicated in cognition and AD, is not clear. Third, whether APP is involved in other stages of neurogenesis in addition to progenitor proliferation has not been explored. Last, cellular mechanisms governing the role of APP in neurogenesis is poorly understood. Here, we addressed these questions by monitoring proliferation, fate decision, and maturation of newborn neurons in the dentate gyrus of mice lacking APP globally or in specific neuronal populations. We revealed increased proliferation of neural progenitor cells in $\mathrm{APP}^{-/-}$mice, and this is accompanied by reduced tonic GABA current recorded from GCs of the hippocampus. Our results support the notion that APP exerts negative activity on cell proliferation through regulating ambient GABA release. This view is in agreement with the recent finding that the activity of $\mathrm{PV}+$ interneurons regulates stem cell quiescence via $\mathrm{GABA}_{\mathrm{A}}$ receptor-mediated tonic GABA signaling (Song et al., 2012). In contrast to increased proliferation, the long-term survival of mature newly born neurons was decreased in $\mathrm{APP}^{-1-}$ mice. This could be attributable to their immature morphological features and inability to integrate into the existing network. In light of the reduced long-term survival of newborn neurons, it is possible that increased progenitor proliferation represents a compensatory response to diminished survival.

To fully understand how APP affects different stages of neurogenesis, we used retroviral RFP or GFP labeling to identify

\section{$\leftarrow$}

retrovirus-mediated expression of GFP. $\boldsymbol{E}$, Analysis of total dendritic length showed significant reduction in VGAT KO, but not NEX KO mice. $F$, Sample traces of mIPSCs recorded under the whole-cell voltage clamp. $\boldsymbol{G}, \boldsymbol{H}$, Quantification of mean frequency $(\boldsymbol{G})$ and amplitude $(\boldsymbol{H})$ of GABAergic synaptic transmission recorded in GCS of $v G A T$ KO and controls (Ctr), showing reduced $\mathrm{mIPSC}$ frequency but normal amplitude in VGAT KO mice. $N=7-9$ slices from at least 5 animals per genotype; ${ }^{*} p<0.05$ (Student's $t$ test). I, J, Behavioral test for discrimination between similar contexts $A$ and $B$ in control and vGAT KO mice. For experimental design, please see Materials and Methods for detailed information. I, All groups showed negligible levels of freezing before a single footshock (Day 0 ). vGAT KO mice displayed similar level of conditioning to training context A compared with Ctr (Day 1). I, Percentage of freezing of Ctr and vGAT KO mice over $4 \mathrm{~d}$ of the experiment. $N=6-10$ animals per genotype; ${ }^{*} p<0.05$ (two-way ANOVA). Values represent mean \pm SEM. Scale bars: $\boldsymbol{A}, \boldsymbol{B}, 100 \mu \mathrm{m} ; \boldsymbol{D}, 20 \mu \mathrm{m}$. 
changes in dendritic complexity and branching of neurons lacking APP. We found that the adult-born GCs in $\mathrm{APP}^{-1-}$ mice display impaired morphology starting from 2 wpi and continues onward. Earlier work has shown that abolishing GABA-induced depolarization can result in defects in dendritic growth and synapse formation during adult neurogenesis (Ben-Ari, 2002; Owens and Kriegstein, 2002; Ge et al., 2007). These studies provide support that reduced mIPSC and GABAergic stimulation to GCs in the absence of APP may underlie the impaired dendritic maturation of adult-born neurons of APP ${ }^{-1-}$ mice. The fact that APP expression is highly enriched in GABAergic interneurons and that deletion of APP in GABAergic interneurons, but not in progenitor cells or glutamatergic neurons, recapitulates the neurogenic deficits of $\mathrm{APP}^{-1-}$ mice provides compelling evidence for the notion that GABAergic APP functions as an extrinsic factor in maintaining proper neurogenesis.

\section{APP controls GABAergic neurotransmission through presynaptic mechanisms}

Adult hippocampal neurogenesis is tightly regulated by neuronal activity, particularly by the balance of GABAergic versus glutamatergic inputs (Zhao et al., 2008). The role of APP in hippocampal GABAergic synaptic transmission has been suggested in earlier studies showing that aged APP ${ }^{-/-}$mice exhibit LTP deficits that were associated with an alteration in paired-pulse depression of GABA-mediated IPSCs (Seabrook et al., 1999), and the LTP deficits could be reversed with blockage of $\mathrm{GABA}_{\mathrm{A}}$ receptors (Fitzjohn et al., 2001). In addition, we have previously reported that synaptic properties of GABAergic neurons including paired-pulse inhibition and post-tetanic potentiation were affected in both striatal and hippocampal GABAergic neurons of $\mathrm{APP}^{-1-}$ mice through presynaptic modulation of $\mathrm{Ca}(\mathrm{v}) 1.2$ (Yang et al., 2009), indicating an indispensable role of APP in regulating GABAergic synaptic transmission through presynaptic mechanism. In contrast, APP has not been shown as an essential regulator in controlling excitatory synaptic strength as a few earlier studies reported normal efficacy of excitatory hippocampal synapses both in dentate gyrus and area CA1 of $\mathrm{APP}^{-1-}$ mice (Seabrook et al., 1999; Ring et al., 2007; Jedlicka et al., 2012). In the current study, we discovered significant reduction of GABAergic synaptic transmission in GCs of $\mathrm{APP}^{-1-}$ mice without affecting glutamatergic synaptic transmission, leading to an imbalanced input to GCs and compromised newborn neuron development. Moreover, reduced tonic conductance, mediated by the spillover of synaptically released GABA, may also contribute to impairment of the inhibitory hippocampal network in $\mathrm{APP}^{-1-}$ mice as tonic GABAergic currents control network excitability in dentate gyrus GCs (Farrant and Nusser, 2005). Although a potential role of $\mathrm{Ca}(\mathrm{v}) 1.2$ in APP-mediated adult neurogenesis is not clear, these results combined indicate that APP, highly expressed in GABAergic interneurons in the hippocampus, may serve as a critical mediator in maintaining a delicate balance of excitatory versus inhibitory inputs through GABAergic modulation in the normal brain.

\section{APP dysfunction and pattern separation}

In this study, we have not only revealed the mechanism of APP in regulation of the different stages of neurogenesis but also the behavioral consequences of altered adult hippocampal neurogenesis. Recent studies have implicated adult-born hippocampal neurons in pattern separation, a process to distinguish and store similar experiences or events as distinct, nonoverlapping memories (Clelland et al., 2009; Sahay et al., 2011; Nakashiba et al.,
2012). Young adult-born GCs, together with robust inhibition by interneurons residing in the hilus and the GrL, generate a sparse pattern of dentate gyrus GC activation that allows inputs of similar contextual representations to be distributed into nonoverlapping populations of GCs (Kheirbek et al., 2012). Impaired pattern separation may result in overgeneralization, which is a common feature of anxiety disorders, specifically post-traumatic stress disorders (Kheirbek et al., 2012). A recent study presented evidence that $\mathrm{AD}$ patients exhibit pattern-separation deficits that are related both to APOE 4 genotypes and CSF A $\beta 42$ levels, consistent with disrupted activity in the hippocampal dentate gyrus (Wesnes et al., 2014). Our findings of defective neurogenesis and pattern separation as a result of APP loss of function raises the possibility that APP dysfunction caused by overexpression or mutations may alter the process of adult hippocampal neurogenesis and hippocampal-dependent episodic memory, specifically in pattern separation.

In conclusion, studies presented here identify APP as an extrinsic physiological regulator of adult hippocampal neurogenesis by modulating GABAergic stimulation of the neurogenic niche. Further, we reveal behavioral consequences of APP dysfunction in GABA signaling and impaired network plasticity. We believe that these important insights emerging from our current study will have significant impact on our understanding of $\mathrm{AD}$ pathogenesis.

\section{References}

Abrous DN, Koehl M, Le Moal M (2005) Adult neurogenesis: from precursors to network and physiology. Physiol Rev 85:523-569. CrossRef Medline

Ben-Ari Y (2002) Excitatory actions of GABA during development: the nature of the nurture. Nat Rev Neurosci 3:728-739. CrossRef Medline

Caillé I, Allinquant B, Dupont E, Bouillot C, Langer A, Müller U, Prochiantz A (2004) Soluble form of amyloid precursor protein regulates proliferation of progenitors in the adult subventricular zone. Development 131: 2173-2181. CrossRef Medline

Chao HT, Chen H, Samaco RC, Xue M, Chahrour M, Yoo J, Neul JL, Gong S, Lu HC, Heintz N, Ekker M, Rubenstein JL, Noebels JL, Rosenmund C, Zoghbi HY (2010) Dysfunction in GABA signalling mediates autismlike stereotypies and Rett syndrome phenotypes. Nature 468:263-269. CrossRef Medline

Chuang TT (2010) Neurogenesis in mouse models of Alzheimer's disease. Biochim Biophys Acta 1802:872-880. CrossRef Medline

Clelland CD, Choi M, Romberg C, Clemenson GD Jr, Fragniere A, Tyers P, Jessberger S, Saksida LM, Barker RA, Gage FH, Bussey TJ (2009) A functional role for adult hippocampal neurogenesis in spatial pattern separation. Science 325:210-213. CrossRef Medline

Demars MP, Bartholomew A, Strakova Z, Lazarov O (2011) Soluble amyloid precursor protein: a novel proliferation factor of adult progenitor cells of ectodermal and mesodermal origin. Stem Cell Res Ther 2:36. CrossRef Medline

Farrant M, Nusser Z (2005) Variations on an inhibitory theme: phasic and tonic activation of GABA(A) receptors. Nat Rev Neurosci 6:215-229. CrossRef Medline

Fitzjohn SM, Morton RA, Kuenzi F, Rosahl TW, Shearman M, Lewis H, Smith D, Reynolds DS, Davies CH, Collingridge GL, Seabrook GR (2001) Agerelated impairment of synaptic transmission but normal long-term potentiation in transgenic mice that overexpress the human APP695SWE mutant form of amyloid precursor protein. J Neurosci 21:4691-4698. Medline

Ge S, Goh EL, Sailor KA, Kitabatake Y, Ming GL, Song H (2006) GABA regulates synaptic integration of newly generated neurons in the adult brain. Nature 439:589-593. CrossRef Medline

Ge S, Pradhan DA, Ming GL, Song H (2007) GABA sets the tempo for activity-dependent adult neurogenesis. Trends Neurosci 30:1-8. CrossRef Medline

Goebbels S, Bormuth I, Bode U, Hermanson O, Schwab MH, Nave KA (2006) Genetic targeting of principal neurons in neocortex and hippocampus of NEX-Cre mice. Genesis 44:611-621. CrossRef Medline

Guo Q, Li H, Gaddam SS, Justice NJ, Robertson CS, Zheng H (2012) Amyloid 
precursor protein revisited: neuron-specific expression and highly stable nature of soluble derivatives. J Biol Chem 287:2437-2445. CrossRef Medline

Ihrie RA, Alvarez-Buylla A (2011) Lake-front property: a unique germinal niche by the lateral ventricles of the adult brain. Neuron 70:674-686. CrossRef Medline

Jedlicka P, Owen M, Vnencak M, Tschäpe JA, Hick M, Müller UC, Deller T (2012) Functional consequences of the lack of amyloid precursor protein in the mouse dentate gyrus in vivo. Exp Brain Res 217:441-447. CrossRef Medline

Kheirbek MA, Klemenhagen KC, Sahay A, Hen R (2012) Neurogenesis and generalization: a new approach to stratify and treat anxiety disorders. Nat Neurosci 15:1613-1620. CrossRef Medline

Lazarov O, Marr RA (2010) Neurogenesis and Alzheimer's disease: at the crossroads. Exp Neurol 223:267-281. CrossRef Medline

Ming GL, Song H (2011) Adult neurogenesis in the mammalian brain: significant answers and significant questions. Neuron 70:687-702. CrossRef Medline

Mu Y, Gage FH (2011) Adult hippocampal neurogenesis and its role in Alzheimer's disease. Mol Neurodegener 6:85. CrossRef Medline

Nakashiba T, Cushman JD, Pelkey KA, Renaudineau S, Buhl DL, McHugh TJ, Rodriguez Barrera V, Chittajallu R, Iwamoto KS, McBain CJ, Fanselow MS, Tonegawa S (2012) Young dentate granule cells mediate pattern separation, whereas old granule cells facilitate pattern completion. Cell 149:188-201. CrossRef Medline

Owens DF, Kriegstein AR (2002) Is there more to GABA than synaptic inhibition? Nat Rev Neurosci 3:715-727. CrossRef Medline

Ring S, Weyer SW, Kilian SB, Waldron E, Pietrzik CU, Filippov MA, Herms J, Buchholz C, Eckman CB, Korte M, Wolfer DP, Müller UC (2007) The secreted beta-amyloid precursor protein ectodomain APPs alpha is sufficient to rescue the anatomical, behavioral, and electrophysiological abnormalities of APP-deficient mice. J Neurosci 27:7817-7826. CrossRef Medline

Sahay A, Scobie KN, Hill AS, O'Carroll CM, Kheirbek MA, Burghardt NS, Fenton AA, Dranovsky A, Hen R (2011) Increasing adult hippocampal neurogenesis is sufficient to improve pattern separation. Nature 472:466470. CrossRef Medline

Seabrook GR, Smith DW, Bowery BJ, Easter A, Reynolds T, Fitzjohn SM, Morton RA, Zheng H, Dawson GR, Sirinathsinghji DJ, Davies CH, Collingridge GL, Hill RG (1999) Mechanisms contributing to the deficits in hippocampal synaptic plasticity in mice lacking amyloid precursor protein. Neuropharmacology 38:349-359. CrossRef Medline

Sernagor E, Chabrol F, Bony G, Cancedda L (2010) GABAergic control of neurite outgrowth and remodeling during development and adult neurogenesis: general rules and differences in diverse systems. Front Cell Neurosci 4:11. CrossRef Medline

Song J, Zhong C, Bonaguidi MA, Sun GJ, Hsu D, Gu Y, Meletis K, Huang ZJ, Ge S, Enikolopov G, Deisseroth K, Luscher B, Christian KM, Ming GL, Song H (2012) Neuronal circuitry mechanism regulating adult quiescent neural stem-cell fate decision. Nature 489:150-154. CrossRef Medline

Tanzi RE (2012) The genetics of Alzheimer disease. Cold Spring Harb Perspect Med 2: a006296. CrossRef Medline

Tashiro A, Zhao C, Gage FH (2006) Retrovirus-mediated single-cell gene knockout technique in adult newborn neurons in vivo. Nat Protoc 1:3049-3055. Medline

Tozuka Y, Fukuda S, Namba T, Seki T, Hisatsune T (2005) GABAergic excitation promotes neuronal differentiation in adult hippocampal progenitor cells. Neuron 47:803-815. CrossRef Medline

Treves A, Tashiro A, Witter MP, Moser EI (2008) What is the mammalian dentate gyrus good for? Neuroscience 154:1155-1172. CrossRef Medline

Wang Z, Wang B, Yang L, Guo Q, Aithmitti N, Songyang Z, Zheng H (2009) Presynaptic and postsynaptic interaction of the amyloid precursor protein promotes peripheral and central synaptogenesis. J Neurosci 29: 10788-10801. CrossRef Medline

Wesnes KA, Annas P, Basun H, Edgar C, Blennow K (2014) Performance on a pattern separation task by Alzheimer's patients shows possible links between disrupted dentate gyrus activity and apolipoprotein [element of] 4 status and cerebrospinal fluid amyloid-03B242 levels. Alzheimers Res Ther 6:20. CrossRef Medline

Winner B, Kohl Z, Gage FH (2011) Neurodegenerative disease and adult neurogenesis. Eur J Neurosci 33:1139-1151. CrossRef Medline

Yang L, Wang Z, Wang B, Justice NJ, Zheng H (2009) Amyloid precursor protein regulates Cav1.2 L-type calcium channel levels and function to influence GABAergic short-term plasticity. J Neurosci 29:15660-15668. CrossRef Medline

Yassa MA, Stark CE (2011) Pattern separation in the hippocampus. Trends Neurosci 34:515-525. CrossRef Medline

Zhao C, Teng EM, Summers RG Jr, Ming GL, Gage FH (2006) Distinct morphological stages of dentate granule neuron maturation in the adult mouse hippocampus. J Neurosci 26:3-11. CrossRef Medline

Zhao C, Deng W, Gage FH (2008) Mechanisms and functional implications of adult neurogenesis. Cell 132:645-660. CrossRef Medline

Zheng H, Koo EH (2011) Biology and pathophysiology of the amyloid precursor protein. Mol Neurodegener 6:27. CrossRef Medline 